Citação da obra:

Pato, M.L. (2021) Turismo no Espaço Rural em Portugal - uma análise quantitativa da oferta e da procura. In Antonnela Carvalho de Oliveira, Cidades, Colecionismo e Museus 2. Capítulo 9, pp. 80-87, Editora Atena, Curitiba, Brasil.

\title{
Turismo no Espaço Rural em Portugal - Uma análise quantitativa da oferta e da procura
}

\author{
Lúcia Pato \\ Instituto Politécnico de Viseu, Escola Superior Agrária, Unidade de Investigação CERNAS e GOVCOOP \\ mljesus@esav.ipv.pt
}

\begin{abstract}
Resumo
Nascido na década de oitenta em Portugal, o turismo no espaço rural (TER) tem vindo gradualmente a afirmar-se no país, quer pelo lado da oferta quer pelo lado da procura. O produto turístico pode constituir-se como complemento ou alternativa a outros produtos turísticos, particularmente o produto de Sol e Mar. Encontra-se disseminado por todo o país, mas é nas regiões interiores e periféricas, que o seu desenvolvimento carece ser particularmente promovido, contribuindo-se assim para atenuar as assimetrias em termos de desenvolvimento turístico. Apesar de alguns efeitos sentidos, as repercussões que têm induzido nos territórios rurais são ainda muito ténues, o que indicia a necessidade de uma política mais adequada às necessidades e características dos diferentes territórios rurais.
\end{abstract}

Palavras-Chave: Turismo no Espaço Rural, Portugal, Oferta, Procura

\section{INTRODUÇÃO}

Desde a década de oitenta, têm sido apontados novos instrumentos e formas de desenvolvimento das áreas rurais. Entre essas novas formas de desenvolvimento sublinham-se as atividades de turismo e lazer, por vezes como complemento à atividade agrícola ou às atividades económicas dos meios rurais.

Por outro lado, o turismo rural tem sido impulsionado pela nova procura turística, sobretudo urbana, que tende a procurar experiências novas, singulares e autênticas. Esta nova procura associa frequentemente o rural a espaço de consumo e não de produção (Figueiredo, 2011), aliás como também muitas vezes transmitido pela comunicação social e pelas redes socias.

Á luz desta nova procura e numa tentativa de diversificação do turismo nacional, o governo português decidiu criar na década de oitenta, especificamente em 1986, o Turismo no Espaço Rural (TER). Efetivamente o produto turístico foi definido como "a atividade de interesse para o turismo, com natureza familiar, que consiste na prestação de hospedagem em casas que 
sirvam simultaneamente de residência aos seus donos" ou representantes (DL nº. 256/86, de 27 agosto), podendo integrar a forma de Turismo de Habitação (TH), Turismo Rural (TR) ou Agroturismo (AG).

Com apenas estas três modalidades e pouco mais de uma centena e meia de casas aquando da criação do produto turístico (Pato, 2012), o TER tem vindo gradualmente a afirmar-se no país, pelo menos por via do número de empreendimentos turísticos, contabilizando-se em 2011 um milhar de empreendimentos (Pato, 2012) e em 2017 cerca de 1400 empreendimentos de TER/TH (INE, 2018). A acompanhar a oferta em termos de empreendimentos, a procura tem também aumentado, sendo que o número de dormidas nos empreendimentos de TER/TH passou de pouco mais de 50000 dormidas aquando da criação do produto turístico (Pato, 2012), a cerca de 1,7 milhões em 2017 (INE, 2018).

Com base nos dados fornecidos pelo Turismo de Portugal (TP) e através de análises descritivas, o objetivo deste trabalho são o de analisar as tendências de desenvolvimento quantitativo do TER e TH em Portugal do lado da oferta e da procura e refletir sobre as ténues repercussões da atividade turística.

\section{Metodologia}

Numa primeira fase procedemos à análise da literatura sobre o produto turístico em apreço e as suas repercussões nos territórios rurais. Posteriormente, numa segunda fase, com base nas estatísticas fornecidas pelo Turismo de Portugal acerca do produto turístico, recorreu-se a análises descritivas simples com o intuito de explorar regiões e modalidades de mais e menos oferta/procura turística do produto em apreço.

No entanto é de referir que uma vez que a partir de 2012 os dados passaram a ser recolhidos pelo Instituto Nacional de estatística (INE), não nos sendo possível fazer comparação com dados anteriores a esse ano, sendo este o motivo pelo qual o último ano em análise é 2011.

\section{RESULTADOS}

\section{A EVOluÇão quantitativa da OFERTA TER E do TH EM PORTUgal}

Os primeiros dados estatísticos acerca do TER remontam a $1984^{1}$, sendo que nesse ano foram contabilizadas 103 casas de TH e passados dois anos quando se dá o enquadramento legal da atividade esse número ascendia já a 154 unidades (Figura 1). A partir desse ano, o número de empreendimentos de TER e TH tem aumentado, contabilizando-se em 2011 cerca de um milhar

\footnotetext{
${ }^{1}$ Ano em que surgiram as primeiras estatísticas da Direção Geral de Turismo.
} 
desses empreendimentos. Conforme a Fig. 1 os maiores aumentos deram-se entre 1991 e 1992 e 2001 e 2002, com um aumento positivo de 181 empreendimentos em cada um dos períodos considerados.

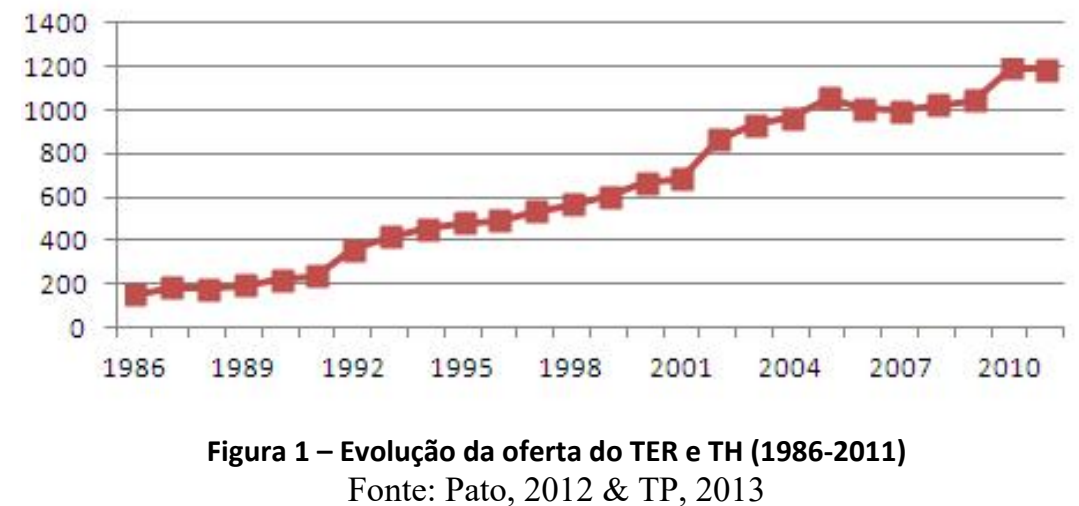

Entre 2004 e 2011 o crescimento da oferta do número de empreendimentos de TER e TH é aliás superior à Hotelaria Tradicional (HT) em 18\%. Embora ainda com um peso minoritário no país, este tipo de oferta adapta-se bem a algumas regiões, das quais se salientam as mais rurais, mas também mais ricas em recursos baseados nas próprias comunidades rurais e no respetivo património histórico, cultural e patrimonial.

\section{Distribuição da oferta do TER e do TH (2007-2011)}

Centrando a análise na distribuição de empreendimentos por regiões (NUTS), o Norte seguido do Centro são as duas regiões com maior número de empreendimentos (Fig. 2). A maior distribuição de empreendimentos no Norte de Portugal não será certamente alheia ao facto da associação de turismo rural mais antiga e com mais notoriedade do país (TURIHAB) estar sediada nesta região. Por outro lado, ambas as regiões possuem potencialidades únicas para a promoção deste tipo de turismo, o que pode também ter estimulado muitas pessoas a aderirem à atividade.

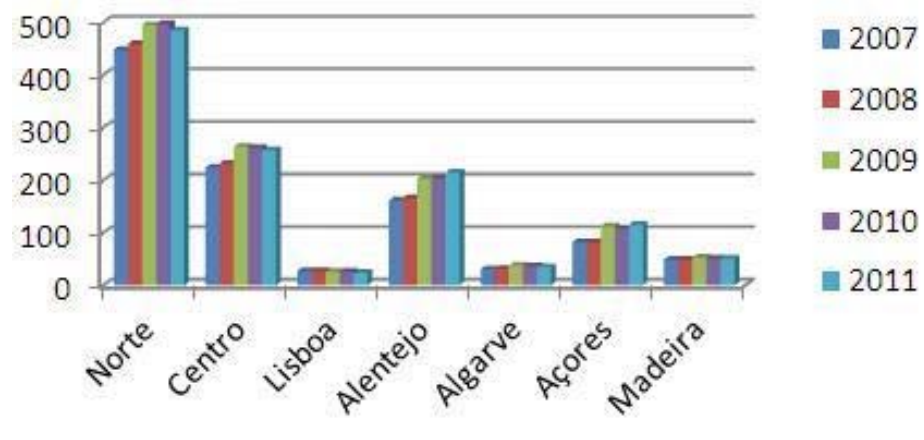

Figura 2 - Oferta no TER e TH por região (2007-2011) 
Na região Norte destaca-se desde logo a presença do rio Douro, a paisagem do Alto Douro Vinhateiro, o parque nacional Peneda Gerês, o património arqueológico de Foz Côa, a riqueza da região em termos gastronómicos e vinhos (exemplo do vinho do Porto). Na região Centro, destaca-se igualmente a paisagem, o Parque Natural da Serra da Estrela e a riqueza em termos de gastronomia e vinho (por exemplo o vinho do Dão).

Em ordem inversa em termos do número de empreendimentos, afigura-se Lisboa e o Algarve, regiões onde a hotelaria tradicional aliada ao produto city breaks (em Lisboa) e "turismo de sol e mar" (no Algarve) tem um peso manifestamente preponderante (TP, 2007).

No que diz respeito à distribuição por tipo de empreendimentos no quinquénio em análise, observa-se que a modalidade $\mathrm{CC}$ é a mais popular em termos do número de empreendimentos, seguida do TH (Fig. 3).

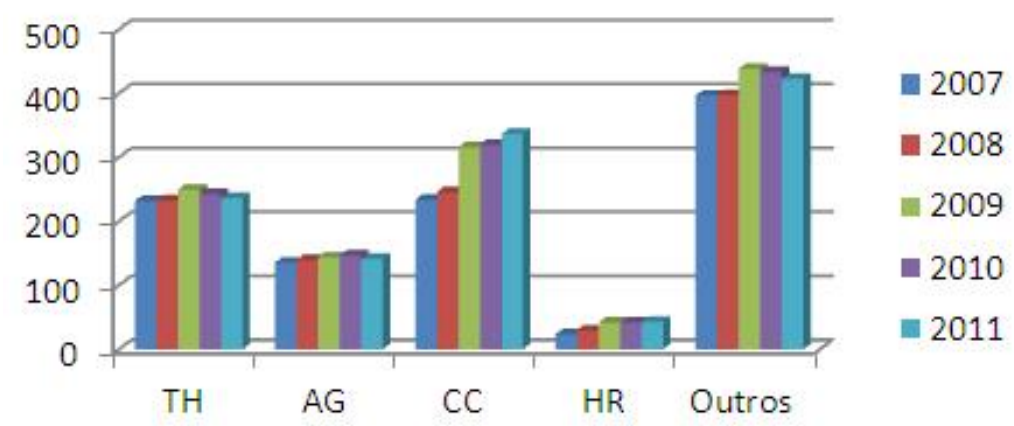

Figura 3 - Oferta no TER e TH por modalidade (2007-2011)

Nota: "Outros" inclui as modalidades TR e turismo de aldeia (TA) que ainda não se reconverteram. Fonte: TP, 2013

Uma vez que as CC são menos exigentes em termos da qualidade dos edifícios e do seu recheio, a maior representatividade da modalidade poderá indiciar o acesso à atividade por parte das famílias rurais portuguesas menos abastadas economicamente. Por outro lado, o peso que o TH continua ainda a possuir enquanto modalidade de alojamento originalmente integrada no TER, indicia que (devido às exigências em termos da qualidade dos edifícios e do seu recheio), muitos dos seus promotores continuam certamente a pertencer a famílias com recursos patrimoniais. $\mathrm{Na}$ análise efetuada vale a pena ainda observar que o AG, embora ainda que de forma modesta, tem vindo a perder popularidade. Sendo esta modalidade aquela que mais de perto se relaciona com a atividade agrícola, apraz-nos perguntar qual tem vindo a ser o papel da agricultura e das respetivas atividades agrícolas no desenvolvimento do produto turístico? 


\section{A eVoluÇão Quantitativa da Procura do TER e do TH em Portugal}

A procura pelo TER e do TH ao longo deste quarto de século teve uma evolução igualmente considerável.

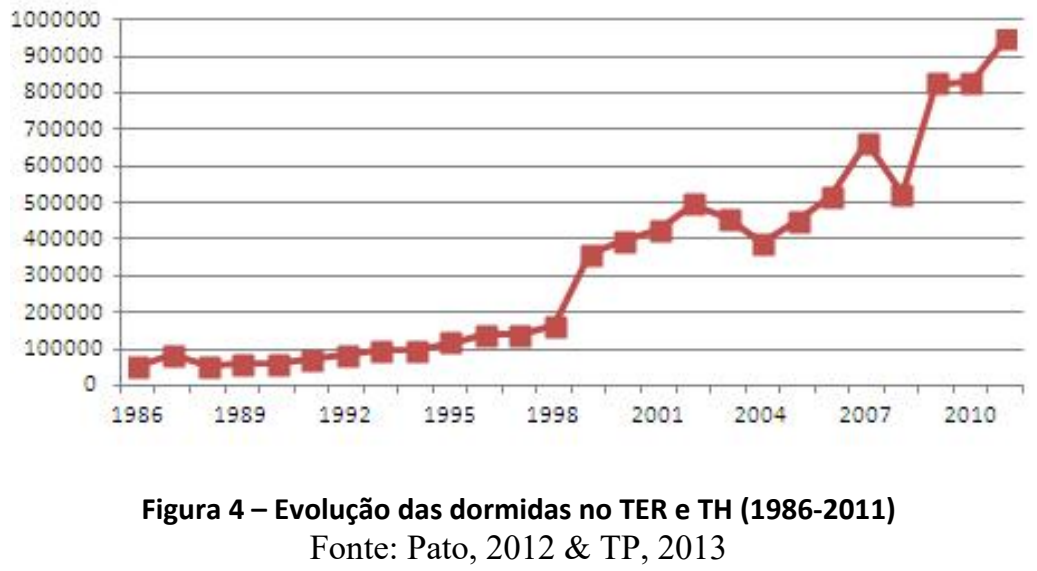

Em 1986 quando se deu o enquadramento legal da atividade o número de dormidas ascendia já a 53126, sendo que daí até agora o número de dormidas neste tipo de empreendimentos não parou de crescer. Em 2011 contabilizaram-se cerca de 948700 dormidas nestes empreendimentos (Figura 4).

Sublinha-se que o grande aumento de dormidas nestes empreendimentos verifica-se a partir de $1998^{2}$ e particularmente nos últimos três anos em análise. Esta grande procura deve-se provavelmente à consciência cada vez maior dos benefícios deste tipo de atividade em relação a outros tipos de turismo. Por outro lado, os recentes atentados terroristas que tem deixado um rasto de morte um pouco por todo o mundo e que podem afastar as pessoas de locais habitualmente mais procurados, poderão ajudar a explicar este interesse crescente pelo TER e TH.

\section{Distribuição da procura do TER e do TH (2007-2011)}

Centrando agora a análise de dormidas por região, verifica-se que o Norte e o Alentejo são as duas regiões com maior número de dormidas no TER e TH (Fig. 5). Este dado não será certamente alheio ao facto de ambas as regiões possuírem enormes potencialidades para o touring cultural e paisagístico e para a gastronomia e vinhos (TP, 2007).

\footnotetext{
${ }^{2}$ Não obstante a quebra verificada em alguns anos, particularmente em 2004 e 2008.
} 


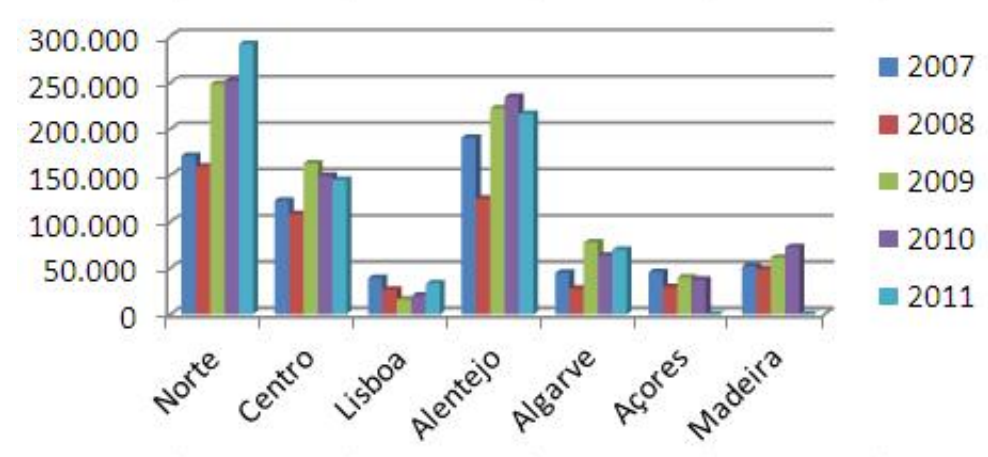

Figura 5 - Evolução das dormidas no TER e TH por região (2007-2011) Fonte: TP, 2013

Ao mesmo tempo, o facto de ambas as regiões possuírem estruturas profissionais ${ }^{3}$ de apoio à dinamização da oferta turística e bem assim de apoio à promoção e comercialização dessa oferta, poderá explicar a maior procura pelo turismo rural.

Em termos da procura no quinquénio 2007-2011, verifica-se que as dormidas nas CC prevalecem, logo seguidas das dormidas nos HR. Observa-se também que a modalidade de AG, no global, é a menos procurada pelos turistas (Fig. 6).

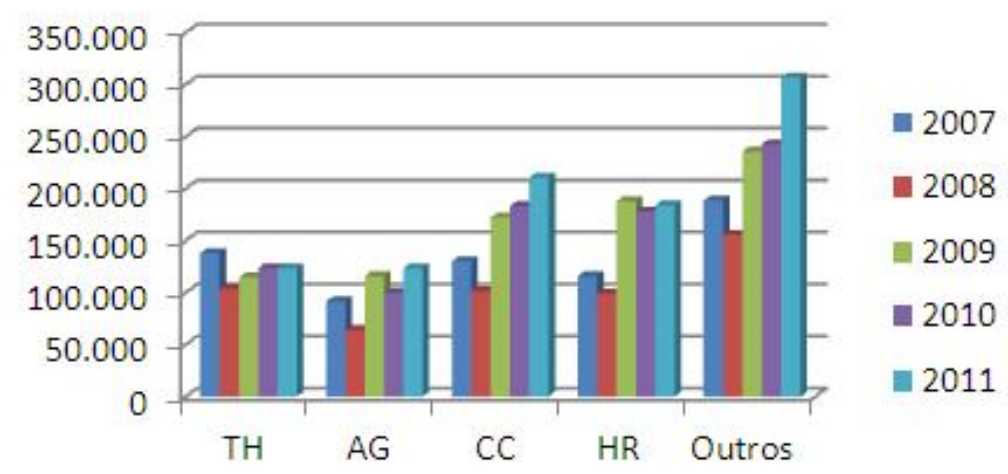

Figura 6 - Evolução das dormidas no TER e TH por modalidade (2007-2011)

Nota: "Outros" inclui as modalidades TR e turismo de aldeia (TA) que ainda não se reconverteram Fonte: TP, 2013

Apesar disto, as taxas de ocupação-cama continuam ainda a ser relativamente baixas no TER e no TH, situando-se em 2011 nos 17,1\% (TP, 2013).

\section{CONCLUSÃo}

A análise quantitativa dos dados evidencia o crescimento quer da oferta quer da procura do TER e TH. Pelas suas potencialidades, há no entanto determinadas regiões onde essa oferta e

\footnotetext{
${ }^{3}$ Especificamente, a TURIHAB E A CENTER que estão localizadas no Norte, e a associação Casas Brancas sediada no Alentejo.
} 
consequentemente a procura é mais evidente. O Norte e o Centro em termos de oferta de empreendimentos e o Norte e o Alentejo em termos da procura. Se o produto turístico se revela como extremamente importante para determinadas regiões, sobretudo as mais rurais e mais interiores, sob o nosso ponto de vista poderia ser mais enfatizado nas estratégias de desenvolvimento nacional de Turismo. Com efeito o produto turístico só de forma muito ténue foi referido no Plano Nacional de Turismo, parecendo aliás integrar outros produtos turísticos. Por outro lado, as repercussões que a oferta e a procura têm gerado nos próprios territórios são ainda muito ténues (Pato, 2012), o que mais uma vez indicia a necessidade de políticas mais adequadas às necessidades e características dos diferentes territórios.

\section{Bibliografia}

Figueiredo, E. (2011). Um rural cheio de futuros? In E. Figueiredo (Ed.), Rural Plural (pp. 1319). Castro Verde: 100Luz.

Pato, L. (2012). Dinâmicas do turismo rural - impactos em termos de desenvolvimento rural. PhD thesis, Universidade de Aveiro, Aveiro.

TP. (2007). Plano Estratégico Nacional para o Turismo. Lisboa: TP.

TP. (2013). Anuário das Estatísticas de Turismo 2012. Lisboa: TP. 